Revista de Estudios Histórico-Jurídicos

[Sección historia del derecho chileno]

XLIII (Valparaíso, Chile, 2021)

[pp. 571-586]

\title{
LAS PROHIBICIONES PROBATORIAS EN LA OBRA DE ERNST BELING: DETERMINANDO SU ALCANCE E INCIDENCIA EN EL SISTEMA PROCESAL PENAL CHILENO*
}

[Evidence restrictions in Ernst Beling's work: determining its scope and incidence in Chilean criminal procedure system]

\author{
Carlos Correa Robles* \\ Universidad Adolfo Ibáñez, Chile
}

\begin{abstract}
RESUMEN
ABSTRACT

El trabajo busca analizar el origen y contexto histórico-jurídico en el cual se concibió la teoría de las prohibiciones probatorias, inicialmente propuesta por el jurista alemán Ernst Beling. Asimismo, se expondrá la incidencia que dicha propuesta ha tenido en la doctrina y jurisprudencia chilena.

Palabras clave

Prueba ilícita - prohibiciones de prueba - proceso penal

This work look analyze the origin and historical-legal context in which the theory of exclusionary rules was conceived, initially proposed by the German jurist Ernst Beling, likewise, will be presented the impact that said proposal has had on Chilean doctrine and jurisprudence.

\section{KeY Words}

Illegally or wrongful evidence restrictions of evidence - criminal procedure
\end{abstract}

RECIBIDO el 22 de enero de 2020 y ACEPTADO el 26 de septiembre de 2021

* Lista de abreviaciones: Diss. = Tesis Doctoral; DriZ. = Deutsche Richterzeitung; GJ. = Gaceta Jurídica; JURA. = Juristische Ausbildung; JZ. = JuristenZeitung; LALS. = Latin American Legal Studies; NJW. = Neue Juristische Wochenschrift; Pol. Crim. = Revista Política Criminal; RDJ. = Revista de Derecho y Jurisprudencia; RDPUCV. $=$ Revista de Derecho de la Pontificia Universidad Católica de Valparaíso; RG. = Reichsgericht; StPO. = Strafprozessordnung; StraFo. $=$ StrafverteidigerForum; $S t V .=$ Strafverteidiger; $Z S t W .=$ Zeitschrift für die gesamte Strafrechtswissenschaft.

** Dr. Iur. y LL.M. Freie Universität Berlin, Profesor Asistente, Universidad Adolfo Ibáñez, c.correa@uai.cl. ORCID 0000-0002-6006-4255. Una versión preliminar de este trabajo fue expuesta el día 7 de noviembre de 2019 en las XVI Jornadas Chilenas de Derecho Penal y Ciencias Penales. Este artículo es parte de una investigación financiada mediante un proyecto Fondecyt Iniciación ( N 11190036: "La prueba ilícita en el proceso penal: más allá de la regla de exclusión”, 2019-2022) cuyo apoyo agradezco en esta nota. Mis agradecimientos van igualmente a Catalina Correa Uribe por su valiosa ayuda en la edición de este texto y a los árbitros anónimos por sus sugerencias, correcciones y comentarios. 


\section{INTRODUCCIÓN}

El indiscutible desarrollo alcanzado por las ciencias penales en los últimos 150 años, se debe en parte importante, al significativo aporte efectuado por diversos juristas formados en la tradición jurídica del Segundo Imperio Alemán. Entre ellos destaca Ernst Beling, nacido en Glogovia en 1866, recordado hasta nuestros días fundamentalmente por sus innegables contribuciones al desarrollo de la teoría del tipo penal, concepto construido principalmente a partir su monumental obra $\mathrm{La}$ Teoría del Delito ("Die Lehre vom Verbrechen”), cuya publicación se remonta a 1906.

La obra de este jurista se desarrolló, sin embargo, más allá de la parte general del derecho penal, abarcando con gran dedicación otro aspecto de las ciencias penales: el proceso penal. Su tratado sobre la materia, editado originalmente en 1928, constituye la culminación de 35 años de una ininterrumpida labor docente en dicha área del derecho.

Mucho antes de dicha publicación, en los albores de su carrera académica tras aceptar su designación como catedrático en la Universidad de Tübingen, señalaba Beling que: "La existencia humana, imperfecta como es, está basada en la verdad y el error, y como tal, todos los pensamientos del hombre son en último término una lucha contra el error, una batalla por la verdad"2.

Con estas palabras iniciaba el autor su conferencia inaugural pronunciada en la referida casa de estudios, posteriormente publicada como monografía bajo el título "Die Beweisverbote als Grenze der W abrheitsforschung im Strafprozess". ("Las prohibiciones probatorias como límites a la averiguación de la verdad en el proceso penal") $)^{3}$. Aquella conocida conferencia constituyó el punto de partida del desarrollo de la teoría de las denominadas prohibiciones probatorias en Alemania, cuya relevancia y aplicación se extiende hasta nuestros días, influyendo incluso -como se expondrá posteriormente- en países tan lejanos como el nuestro.

Ahora bien, a pesar de la indiscutida trascendencia histórica que transversalmente se atribuye la propuesta de Beling como pilar fundamental de lo que entre nosotros denominamos genéricamente como prueba ilícita, existe (tanto en Chile como en Alemania) un generalizado desconocimiento tanto del contenido, como del alcance real de su posición sobre el tema. A esto me referiré a continuación, intentando situar las ideas de Beling en el contexto histórico en el cual estas se desarrollaron.

\footnotetext{
${ }^{1}$ BeLing, Ernst, Die Lehre vom Verbrechen (1906, reimp. Tübingen 2000).

2 "Das menschliche Dasein, unvollkommen wie es ist, ist eingebettet zwischen Wabrheit und Irrtum, und weil es das ist, is alles menschlichen Denken in letater Linie ein Kampf gegen den Irrtum, ein Ringen um die Wabrheif'. BeLING, Ernst, Die Beweisverbote als Grenzen der Wabrheitserforschung im Strafprozess: Sonderausgabe (1903, reimp. Darmstadt, 1968), p. 1. Las traducciones de citas al español contenidas en este trabajo, son de mi autoría.

${ }^{3}$ Beling, Ernst, Die Beweisverbote als Grenæen, cit. (n. 2), passim.
} 


\section{ORIGEN Y CONTENIDO DE LA TEORÍA DE LAS PROHIBICIONES probatorias DE ERnSt BELING}

Los orígenes de la mencionada conferencia inaugural resultan poco claros, siendo, sin embargo, la originalidad del tema indiscutida. Posiblemente, como sostuvo uno de sus asistentes (Christoph Hübner) en una glosa introducida a la edición escrita de la referida conferencia ${ }^{4}$, la inspiración de su maestro habría provenido de un pasaje del manual de Julius Glaser, escrito 20 años antes, en el cual dicho autor, refiriéndose a la -entonces novedosa- libre valoración de la prueba, habría esbozado la posibilidad de limitar dicha regla por medio del reconocimiento de exclusiones probatorias, generadas en caso de producirse un incumplimiento de ciertos requisitos procedimentales formales vinculados a la obtención de elementos de prueba ${ }^{5}$. Sin perjuicio de dicho precedente, la tesis de Beling resultó, como veremos, completamente original y rupturista respecto de la postura hasta entonces sostenida por la jurisprudencia.

En lo medular, la tesis de Beling sobre el contenido y efecto de las prohibiciones probatorias, puede ser resumida en tres puntos centrales ${ }^{6}:$ i) no puede obtenerse un medio de prueba en vulneración a reglas establecidas por el legislador, que expresamente impiden el empleo de determinados mecanismos de producción de éste. Su infracción generará lo que el autor denomina un medio de prueba prohibido; ii) en caso que dicha vulneración tenga lugar, y cuando el error sea detectado oportunamente, no podrá el medio de prueba así obtenido ser considerado en la sentencia por el tribunal penal, debiendo éste ser -en consecuencia- ignorado por el juez. El sentenciador deberá consecuentemente considerar dicho resultado probatorio como no acontecido; iii) en caso que el defecto no haya sido advertido en la sentencia, será ésta impugnable por medio del recurso de revisión (el equivalente alemán a nuestro recurso de nulidad).

$\mathrm{Al}$ respecto, de los tres ejes precedentemente mencionados, sólo el segundo de ellos ha mantenido hasta hoy su vigencia ${ }^{7}$. En efecto, la necesidad de respetar reglas sobre obtención de prueba (punto 1) resulta hoy en día algo tan evidente e indiscutido, que deviene en trivial. Respecto al tercer punto, a partir de la década de 1970, la tendencia en la doctrina y jurisprudencia ha sido dejar de percibir las prohibiciones de prueba como reglas controlables exclusivamente por medio del recurso de revisión, para entenderlas como parte integrante de una teoría unitaria, que obliga a reconocer y sancionar prohibiciones probatorias en cualquier etapa del procedimiento ${ }^{8}$.

${ }^{4}$ Ibíd., p. 4, nota al pie 1.

${ }^{5} \mathrm{Al}$ respecto, vid. RogALl, Klaus, Grundsat: fragen der Beweisverbote, en HöPFL, Frank; HüBER, Barbara (eds.), Beweisverbote in Ländern der EU und vergleichbaren Rechtsordnungen, Exclusion of Evidence Within the EU and Beyond, Europäisches Kolloquium Wien, 18. - 20. September 1997 (Freiburg i. Br., 1999), p. 124.

${ }^{6}$ Dicha sistematización corresponde a DALLMEYER, Jens, Beweisfübrung im Strengbeweisverfahren (Norderstedt, 2008), pp. 24 s.

${ }^{7}$ Ibíd., pp. 24 s.

${ }^{8} \mathrm{Al}$ respecto, vid: DallmeYer, Beweisführung im Strengbeweisverfahren, cit. (n. 6), pp. 78 s.; DENCKER, Friedrich, Über Heimlichkeit, Offenheit und Täuschung bei der Beweisgewinnung im Strafverfah- 
Es entonces, la conclusión indicada precedentemente bajo el número ii), aquella que, entendida hoy en día bajo el concepto de prohibiciones de prueba dependientes ${ }^{9}$, cobra la mayor importancia teórica y práctica.

Respecto a este punto, sostenía BeLing que: "La prohibición legal de producción de un medio de prueba cierra un determinado camino en la rendición de prueba y contiene en consecuencia la prohibición de considerar dicha prueba, obtenida antijurídicamente" 10 .

La novedad de dicha tesis, como veremos, radica en el cambio de paradigma que ésta introdujo en la concepción misma del proceso penal, pese a la existencia, ya entonces, de un equivalente funcional (en cuanto a sus efectos en la sentencia definitiva) en la antigua jurisprudencia del Tribunal Imperial alemán.

En dos sentencias dictadas a fines del siglo XIX, en los primeros años de vigencia de la Ordenanza Procesal Penal (StPO), resolvió el entonces máximo tribunal alemán (RG) que la declaración de un testigo no informado oportunamente respecto de su derecho (legalmente consagrado) a no declarar en perjuicio de familiares ni de sí mismo, constituía un medio de prueba inutil, y que por ello no debía ser considerada por el tribunal al momento de dictar sentencia. Nada muy distinto, pensará el lector, de la tesis de Beling recién expuesta. Por el contrario, la distinción esencial entre ambas posiciones, y en la cual radica el verdadero mérito de la propuesta del discípulo de Hugo Meyer, está en la fundamentación de dicha restricción probatoria: para el desaparecido Tribunal Imperial, el elemento central para no considerar dicha prueba en la sentencia radicaba en la ilegalidad

ren - Anmerkungen aus Anlaß zweier Entscheidungen des BGH -, en $S_{T} V$., 5 (1994), p. 670; DeNCKER, Friedrich, Verwertungsverbote im Strafprozeß: ein Beitrag zur Lebre von den Beweisverboten (Köln, 1977), pp. 53, 75; EISENBERG, Ulrich, Beweisrecht der StPO: Spęialkommentar (München, 2015), números al margen 334, 356 y 635; Hengstenberg, Achim, Die Frübwirkung der Verwertungsverbote: eine Untersuchung der Bedeutung der Beweisverwertungsverbote für die strafprozessualen Verdachtsbeurteilungen (Hamburg, 2007) pp. 30 s.; KNAUTH, Alfons, Beweisrechtliche Probleme bei der Verwertung von Abbörmaterial im Strafverfahren, en NJW., 14 (1978), pp. 742 s.; MAul, Heinrich; EschelBACH, Ralf, "Widerspruchslösung" von Beweisverbotsproblemen in der Rechtsprechung, en StraFo., (Mayo/Junio 1996), p. 69; РітsсH, Christoph, Strafprozessuale Beweisverbote: eine systematische, praxisnabe und rechtsvergleichende Untersuchung unter besonderer Berücksichtigung des Steuerstrafverfahrens, der Zufallsfunde und der Fernwirkungsproblematik (Hamburg, 2009), p. 83; RogALL, Klaus, Grund und Grenzen der "qualifizierten” Belebrung im Strafprozess, en GeISLERn, Claudius; KraAtz, Erik; Kretschmer, Joachim; SCHNEIDER, Hartmut; Sowada, Christoph (eds.), Festschrift für Klaus Geppert zum 70. Geburtstag am 10. März 2011 (Berlin, 2011), p. 536; Rogall, Klaus., Beweisverbote in Ländern der EU, cit. (n. 5), p. 130; Rogall, Klaus, Gegenwärtiger Stand und Entwicklungstendenzen der Lebre von den strafprozessualen Beweisverboten, en ZStW., 91 (1979), pp. 7 y s.; Schlothauer, Reinhold, Zur Bedeutung der Beweisverwertungsverbote im Ermittlungs- und Zwischenverfahren, en PRITTwITZ, Cornelius; BAuRMANn, Michael; Günther, Klaus; Kuhlen, Lothar; Merkel, Reinhard; Nestler, Cornelius; Schulz, Lorenz (eds.), Festschrift für Klaus Lüderssen zum 70. Geburtstag am 2. Mai 2002 (Baden-Baden, 2002), pp. 761 ss.; STÖRMER, Rainer, Strafprozessuale Verwertungsverbote in verschiedenen Konstellationen, en JURA., 8 (1994), p. 625; STÖRMER, Rainer, Dogmatische Grundlagen der Verwertungsverbote: eine Untersuchung über die Strukturen strafprozessualer Verwertungsverbote unter dem Einfluss der Verfassung und der Grundsätze des öffentlichen Rechts (Marburg, 1992), pp. 241 y 394.

${ }^{9} \mathrm{Vid}$. Ambos, Kai, Las probibiciones de utilización de pruebas en el proceso penal alemán - fundamentación teórica y sistematización, en Polit. Crim., 7 (2009), pp. 5 ss.

${ }^{10}$ Beling, Ernst, Die Beweisverbote als Grenzen, cit. (n. 2), pp. 3 s. 
cometida en su producción, la cual transformaba el contenido mismo de la declaración en un resultado probatorio no confiable. Si la correcta averiguación de la verdad constituía la finalidad (exclusiva) del proceso penal en aquel entonces, la declaración de un testigo incapaz de controlar las consecuencias de sus dichos, generará un medio de prueba de dudosa veracidad ${ }^{11}$, tal y como por ejemplo lo sería - en ciertos casos- la declaración de un imputado obtenida mediante tortura. De este modo, como resulta lógico concluir, el Tribunal Imperial no necesitaba de un reconocimiento de prohibiciones probatorias para arribar al mismo resultado que Beling.

Así, si bien el autor aquí analizado llega a una conclusión materialmente idéntica de la sostenida hasta entonces por la jurisprudencia (no valoración del medio de prueba ilícitamente obtenido), el fundamento para ello resultaba diametralmente distinto del entonces predominante: el interés del legislador al consagrar el derecho de un testigo a guardar silencio en ciertos casos, obedece -señala el autor expresamente- no a la protección de la correcta averiguación de la verdad, sino al resguardo de lo que denomina "valores sociales dignos de respeto", en específico, la protección de la personalidad y la dignidad humana ${ }^{12}$. La regla infringida se erige entonces como un límite $-\mathrm{y}$ no como un entorpecimiento- a la correcta averiguación de la verdad. He ahí el verdadero aporte de Beling.

Dicha fundamentación de las prohibiciones probatorias, adelantada a su tiempo, fue la que permitió décadas más tarde a la doctrina y la jurisprudencia alemana ampliar su alcance a infracciones que no comprometen directamente la veracidad del medio de prueba obtenido, distanciándose definitivamente de la antigua jurisprudencia ya referida. De este modo, resulta posible sancionar hoy en día con una prohibición de valoración, por ejemplo, aquella prueba documental obtenida desde un domicilio sin contar la policía con la autorización de ingreso y registro necesaria. Siendo en estos casos la veracidad del documento ilícitamente incautado indubitada, la no valoración de éste sería algo impensado bajo el razonamiento del Tribunal Imperial, siendo sólo justificable a partir del reconocimiento de límites a la libre valoración de la prueba.

\section{LA FALSA CONCEPCIÓN ILIMITADA DE LA TESIS DE BELING}

Pese a ser reconocida transversalmente por el avance que significó en la comprensión moderna del proceso penal, la posición de Beling ha sido en las últimas décadas de cierto modo caricaturizada, especialmente en relación a un supuesto alcance ilimitado atribuido a su posición sobre el tema. A este respecto, varios autores ${ }^{13}$-entre los que destaca Beulke- han impuesto como un lugar común en la doctrina que el maestro de München defendía una concepción

\footnotetext{
${ }^{11}$ Strate, Gerhard, Rechtshistorische Fragen der Beweisverbote, en II. Strafverteidiger-Frühjabrssymposium 1988 der Arbeitsgemeinschaft Strafrecht des Deutsches Anwaltverein. Wabrheitsfindung und ibre Schranken (Bergisch Gladbach, 1989), p. 17.

${ }^{12}$ Beling, Ernst, Die Beweisverbote als Grenzen, cit. (n. 2), p. 37.

${ }^{13}$ Entre otros: BEuLKE, Werner, Hypothetische Kausalverläufe im Strafverfabren bei rechtswidrigem Vorgehen von Ermittlungsorganen, en ZStW., 103 (1991), p. 658; KeLNHOFER, Evelyn, Hypothetische
} 
amplia, indiferenciada e ilimitada de las prohibiciones probatorias. Al respecto, se atribuye a Beling el reconocimiento amplio de prohibiciones de valoración de prueba, generadas como consecuencia de cualquier infracción que comprometa la capacidad de funcionamiento del sistema procesal penal. Bastaría así, se afirma, con la mera constatación de una ilegalidad cometida en la obtención probatoria, por intrascendente que ésta sea, para dar lugar a una prohibición de valoración del medio de prueba así obtenido.

De este modo, y para diferenciarse de esta doctrina presumiblemente superada, se recalca por estos autores ${ }^{14}$, que actualmente tanto la jurisprudencia como la doctrina prácticamente unánime, afirman que no toda infracción cometida por los órganos persecutores en la obtención de prueba conducirá a una prohibición de valoración de los elementos así obtenidos, sino sólo aquellas que logren satisfacer determinados requisitos adicionales.

Esta pretendida concepción amplia e indiferenciada de las prohibiciones probatorias, atribuida a Beling, constituye tanto un anacronismo, como un error. En efecto, la afirmación comúnmente imputada a dicho autor ${ }^{15}$ y criticada a continuación, de que toda infracción a la legalidad procesal traería aparejada como consecuencia una prohibición de valorar la prueba obtenida como consecuencia de ella, debe ser contextualizada.

Para dimensionar la tesis de Beling resulta necesario analizar la concepción del proceso penal predominante en la Alemania de comienzos del siglo XX, que entendía la averiguación de la verdad como un principio fundamentalmente ilimitado. Dicho énfasis queda claro ya en las primeras páginas de la citada monografía, al sostener el autor que corresponde a una regla no escrita del proceso penal, "el que todos los hechos jurídicamente relevantes deben ser investigados por medio de todos los medios de prueba disponibles".

A partir de dicha comprensión, las prohibiciones de prueba -como el título de la conferencia lo indica expresamente-constituyen limitaciones autoimpuestas por el legislador por medio de la consagración de preceptos prohibitivos, por medio de los cuales expresamente se impide el empleo de un determinado método o resultado probatorio en el proceso penal. De este modo, la percepción de Beling consistía en entender dichas prohibiciones, tal como sostuvo posteriormente en su manual ${ }^{16}$, como excepcionales, limitándolas sólo a aquellas infracciones pro-

Ermittlungsverläufe im System der Beweisverbote (Berlin, 1994), p. 49, nota al pie 9; KoRIATH, Heinz, Über Beweisverbote im Strafprozeß (Frankfurt am Main, 1994), p. 31.

${ }^{14}$ Grünwald, Gerald, Das Beweisrecht der Strafprozeßordnung (Baden-Baden, 1993), p. 142; Herdegen, Gerhard, Bemerkungen zur Lehre von den Beweisverboten, en: II. Strafverteidiger-Frühjahrssymposium 1988 der Arbeitsgemeinschaft Strafrecht des Deutsches Anwaltverein. Wabrheitsfindung und ihre Schranken (Bergisch Gladbach, 1989), p. 115; ScHellhammer, Kurt, Blutentnahme durch Medizinalassistenten, en NJW., 7 (1972), p. 320. En el sentido opuesto, exclusivamente: KüHNE, Hans-Heiner, Strafprozessrecht: eine systematische Darstellung des deutschen und europäischen Strafverfahrensrechts (Heidelberg, 2015), número al márgen 907.4; PETERs, Karl, Strafprozeß: ein Lehrbuch (Heidelberg, 1985), p. 353.

${ }^{15}$ BeLIng, Ernst, Die Beweisverbote als Grenzen, cit. (n. 2), pp. 30 s.

${ }^{16}$ BeLING, Ernst, Deutsches Reichsstrafprozeßrecht: mit Einschluß des Strafgerichtsverfassungsrechts (Berlin, 1928), p. 290 . 
cesales graves, previamente tipificadas ${ }^{17}$. Al respecto sostenía que ${ }^{18}$ : "una acción procesal no autorizada, introduce un elemento torcido al proceso, generando una infracción procesal. Si bien muchas de estas infracciones, una vez cometidas, son consideradas por el legislador como inocuas, se mantienen algunas especialmente graves como intolerables, de modo tal que se genera un derecho de la parte a impugnar una decisión que las considere, o bien podrá el tribunal actuar de oficio, declarando la infracción".

En este entendido, para Beling las prohibiciones probatorias pueden ser de dos clases: prohibiciones absolutas (impiden indagar por cualquier medio de prueba respecto de un tema determinado) o relativas, donde lo vedado dice relación con el empleo de un medio de prueba concreto. Ejemplo de ambas categorías, lo constituyen respectivamente el antiguo $\int 53^{19}$ de la Ordenanza Procesal Penal alemana y distintas leyes modelo de casas dinásticas alemanas ${ }^{20}$, en relación al $\$$ 4 de la ley de entrada en vigencia de la StPO (EStPO $)^{21}$. La primera de dichas disposiciones, en su inciso final, prohibía a los funcionarios públicos divulgar el contenido de documentos oficiales en caso de existir un interés público superior (prohibición absoluta); el segundo caso, impedía a ciertos nobles pertenecientes a las antiguas familias dinásticas, actuar en calidad de testigos en juicio (prohibición relativa). Es precisamente en base a reglas prohibitivas legalmente impuestas como éstas, sobre las cuales, recalcamos, Beling erigió su teoría.

${ }^{17} \mathrm{Al}$ respecto: RogalL, Klaus, Beweiserbebungs- und Beweisverwertungsverbote im Spannungsfeld zwischen den Garantien des Rechtsstaates und der effektiven Bekämpfung von Kriminalität und Terrorismus, en $J Z ., 17$ (2008), p. 819.

${ }^{18}$ BELING, Ernst, Gren₹linien zwischen Recht und Unrecht in der Ausübung der Strafrechtspflege (Tübingen, 1913), pp. 11 ss.

${ }^{19} \int 53$ StPO: "Oeffentliche Beamte, auch wenn sie nicht mehr im Dienste sind, dürfen über Umstände, auf welche sich ibre Pficht zur. Amtsverschwiegenheit bezieht, als Zeugen nur mit Genehmigung ihrer vorgesetzten Dienstbebörde oder der ibnen zuletzt vorgesetzt gewesenen Dienstbebörde vernommen werden. Für den Reichskanzler bedarf es der Genehmigung des Kaisers, für die Minister der Genehmigung des Landesherrn, für die Mitglieder der Senate der freien Hansestädte der Genehmigung des Senats. Die Genehmigung darf nur versagt werden, wenn die Ablegung des Zeugnisses dem Woble des Reichs oder eines Bundesstaates Nachtheil bereiten würde". (Los funcionarios públicos, incluso si ya no están de servicio activo, solo pueden ser interrogados como testigos sobre las circunstancias a las que se refiere su deber de secreto oficial previa aprobación de la autoridad superior de su servicio o la última autoridad de su servicio que fue su superior. Para el Canciller del Imperio, se requiere la aprobación del Emperador, para los ministros la aprobación del Soberano, para los miembros de los Senados de las ciudades hanseáticas libres, la aprobación del Senado. La aprobación solo podrá rechazarse si la declaración pudiera ser perjudicial para el bienestar del Imperio o de un Estado.)

${ }^{20}$ Por ejemplo, la Ley Modelo de Wüttenberg para la entrada en vigencia de la StPO del 4 de marzo de 1879 esteblecía lo siguiente: "das Staatsoberbaupt kann nicht als Zeuge aufgerufen wrden". (El jefe de Estado no podrá ser citado como testigo.)

${ }^{21}$ J. 4. EStPO: "In Ansebung der Landesherren und der Mitglieder der landesherrlichen Familien sowie der Mitglieder der Fürstlichen Familie Hobenzollern finden die Bestimmungen der Strafprozeßordnung nur insoweit Anwendung, als nicht besondere Vorschriften der Hausverfassungen oder der Landesgesetze abweichende Bestimmungen enthalten". (Con respecto a los soberanos y los miembros de las familias reales, así como a los miembros de la Familia principesca Hohenzollern, las disposiciones de la Ordenanza Procesal Penal solo se aplicarán en la medida en que ninguna disposición de las Constituciones de las casas reales o las leyes estatales contengan disposiciones contrarias a ella). 


\section{LOS CAMBIOS EN LA CONCEPCIÓN DEL PROCESO PENAL Y SU INCIDENCIA EN}

Un siglo después, la concepción de la investigación, y en general, de los límites del proceso penal, es precisamente la opuesta. En contra de la antigua opinión predominante a comienzos del siglo XX, en orden a que todas aquellas actuaciones de la investigación que no se encuentren expresamente prohibidas por el legislador resultan jurídicamente permitidas, la posición imperante al día de hoy entiende al modo en el cual se busca el esclarecimiento de los hechos como un asunto previamente delimitado en sus alcances por el legislador ${ }^{22}$.

Para llegar a dicha conclusión, fue necesario que en 1960 el Tribunal Federal Supremo alemán estableciera ${ }^{23}$ como un principio fundamental del proceso penal, reiterado hasta el día de hoy en su jurisprudencia, el que "la verdad en el proceso penal constituye un valor que no puede obtenerse a cualquier precio". A partir de entonces, todo lo que no esté expresamente autorizado o permitido en materia de obtención probatoria, debe entenderse como prohibido. De este modo, al día de hoy, cualquier ataque a derechos y garantías reconocidos por el legislador en pos de la averiguación de la verdad, requerirá de una autorización expresa por parte del legislador ${ }^{24}$. Cualquier actuación de los órganos persecutores fuera de los límites delineados por el legislador para la obtención de prueba, se encuentra actualmente prohibida, pudiendo - eventualmente- generar consecuencias procesales. Consecuentemente, la doctrina alemana ${ }^{25}$ entiende actualmente a los mecanismos legales de obtención probatoria como límites a la actuación de los órganos persecutores.

Dicha noción, dio lugar a la concepción predominante hoy en día, que entiende la posibilidad de reconocer una prohibición de valoración de prueba -en general- a partir de la constatación de la infracción a una norma que regula la producción de ésta ${ }^{26}$, alejándose de este modo del requisito de tipificación legal expresa de la prohibición, exigido por Beling.

\footnotetext{
${ }^{22}$ Por todos: Alsberg, Max; Nüse, Karl-Heinz; Dallmeyer, Jens, Der Beweisantrag im Strafprozess (Köln, 2013), p. 300.

${ }^{23}$ BGHSt 14, 358 (365). Más reciente, en el mismo sentido: BGHSt 58, 301 (309); 51, 285 (290); 47172 (179); 38, 372 (374); 38, 214 (220); 31, 304 (309); 14, 358 (365).

${ }^{24}$ Rogall, Klaus, Gegenwärtiger Stand, cit. (n. 8), pp. 5 s.

${ }^{25}$ Cfr. Gössel, Karl Heinz, Einleitung L, en BeCKer, Jörg-Peter; ERB, Volker; Esser, Robert; Graalmann-Scheerer, Kirsten; Hilger, Hans; Ignor, Alexander (eds.), Löwe-Rosenberg: Die Strafprozeßordnung und das Gerichtsverfassungsgeset: Großkommentar, 27. Ed. Primer Tomo: Introducción, \S 1-47, (Berlin y otros, 2016), número al margen 55; PITSCH, Strafprozessuale Beweisverbote: eine systematische, praxisnahe und rechtsvergleichende Untersuchung unter besonderer Berücksichtigung des Steuerstrafverfahrens, der Zufallsfunde und der Fernwirkungsproblematik, cit. (n. 8), p. 78; RogALL, Klaus, Beweiserbebungs- und Beweisverwertungsverbote im Spannungsfeld, cit. (n. 17), p. 822; Rogall, Klaus, Gegenwärtiger Stand, cit. (n. 8), p. 2.

${ }^{26}$ Los ejemplos paradigmáticos de este tipo de reglas se encuentran en Ambos, Kai, Las probibiciones de utilización, cit. (n. 9), pp. 8 ss.
} 
Producto de este cambio de paradigma en relación con los límites de la investigación, resulta hoy en día impensable la posibilidad de que el legislador regule expresamente -a modo de catálogo- todas aquellas hipótesis en las cuales una actuación investigativa viciada generará una prohibición de valoración de la prueba así obtenida ${ }^{27}$.

Ahora bien, los presupuestos mediantes los cuales actualmente la infracción a una norma que regula la producción de prueba generará una prohibición de valoración de la misma, al no encontrarse regulados por el legislador, constituye el problema más discutido de la teoría de las prohibiciones probatorias en Alemania $^{28}$. En este sentido, una teoría que permita adecuadamente resolver este problema deberá contar con criterios normativos internos que permitan distinguir aquellas infracciones a reglas de producción de prueba procesalmente irrelevantes, de aquellas que generan una prohibición de valoración del medio de prueba así obtenido $^{29}$. A estas dificultades buscan dar respuesta las dos principales teorías desarrolladas en los últimos 50 años en Alemania para distinguir infracciones de ley impunes cometidas por órganos persecutorios en el marco de una investigación, de aquellas que ocasionan una prohibición de valoración, a saber: la teoría del fin de protección de la norma y de la ponderación de intereses, cuyo análisis excede el alcance de este trabajo.

\section{RECEPCIÓN DE LA TEORÍA DE LAS PROHIBICIONES PROBATORIAS EN CHILE}

\section{Las prohibiciones probatorias y el sistema de enjuiciamiento consagrado en el Código de} Procedimiento Penal: un intento frustrado de recepción

La tesis propuesta por Beling hace más de cien años fue concebida originalmente para ser aplicada en un sistema procesal penal como el regulado por la StPO, en el cual el legislador no consagró expresamente (ni ha consagrado, hasta el día de hoy) mecanismos generales de solución a problemas de ilicitud probatoria.

A diferencia de la regla de exclusión de prueba reconocida desde comienzos del siglo XX por la Corte Suprema estadounidense ${ }^{30}$ (sistema en el cual la solución planteada para problemas de prueba obtenida con infracción de garantías reconocidas en distintas Enmiendas a dicha Constitución, se erige en base a una exclusión de la misma), el sistema de prohibiciones probatorias alemán permite ser incorporado a aquellos ordenamientos de raigambre continental en los cuales la exclusión probatoria, ante la ausencia de regla expresa, resulta imposible de normativizar por vía jurisprudencial. En este sentido, como ya se analizó, la

${ }^{27}$ Cfr. Kohlhaas, Max, Beweisverbote im Strafprozeß, en DRiZ., 44 (1966), p. 287. En la jurisprudencia: BGHSt 38, 214 (223).

${ }^{28}$ Cfr. Alsberg, Max; Nüse, Karl-Heinz; Dallmeyer, Jens, Der Beweisantrag im Strafprozess, cit. (n. 22), número al margen 894; CORREA, Carlos, Más allá de la regla de exclusión: probibiciones probatorias en el derecho chileno - con especial referencia al Derecho alemán-, en Polit. Crim., 13 (2018), pp. 149 ss.

${ }^{29}$ GössEL, Karl Heinz, Kritische Bemerkungen zum gegenwärtigen Stand der Lehre von den Beweisverboten im Strafuerfabren, en NJW., 13 (1981), p. 650.

${ }^{30} \mathrm{Al}$ respecto, vid. CorreA, Carlos, La buena fe del agente como excepción a la aplicación de la regla de exclusión-derecho estadounidense y derecho chileno-, en LALS., 2 (2018), pp. 26 ss. 
solución planteada en Alemania para los problemas de ilicitud probatoria se sustenta fundamentalmente a partir del principio de libre valoración de la prueba, el cual permite al tribunal prescindir de la apreciación de ciertos medios de prueba, aduciendo razones vinculadas a la legalidad de su origen.

De manera similar, un caso paradigmático en el cual la teoría de las prohibiciones probatorias podría tener aplicación lo constituye el sistema regulado por el Código de Procedimiento Penal chileno de 1906 (CdPP). Ante la ausencia en dicho cuerpo normativo de una regla de exclusión de prueba de alcance general, los casos de ilicitud probatoria se limitan en dicho cuerpo normativo a algunas pocas disposiciones aisladas, que establecen ciertas prohibiciones de obtención probatoria bajo determinados métodos o circunstancias, reglas de alcance limitado dirigidas en primer término al tribunal, en tanto órgano encargado de dirigir la investigación ${ }^{31}$. En todo caso, si bien el CdPP prohíbe a los persecutores la realización de ciertas actuaciones de investigación (por ejemplo, el ingreso no autorizado a un edificio o recinto cerrado), no reconoce sanción procesal alguna a su infracción ${ }^{32}$.

Precisamente a partir del análisis de dicha estructura (similar a la regulación alemana), hace más de 30 años Jorge Bofill intentó introducir el sistema de prohibiciones probatorias reconocido en Alemania, en nuestra práctica procesal penal. Así, tanto en su tesis doctoral ${ }^{33}$ como en un artículo publicado en 1988 en la Revista de Derecho de la Pontificia Universidad Católica de Valparaíso ${ }^{34}$, Bofill planteó como solución a determinadas infracciones a reglas sobre obtención probatoria el reconocimiento de prohibiciones probatorias respecto de los medios de prueba así obtenidos. En concreto, la propuesta de Bofill se centró fundamentalmente en reconocer prohibiciones de prueba respecto de infracciones cometidas por órganos encargados de la persecución penal (policías y jueces del crimen) referidas especialmente a la declaración del imputado que no ha sido prestada de manera libre y espontánea ${ }^{35}$; las declaraciones de testigos prestadas sin conocimiento de su derecho a no declarar ${ }^{36}$ y la entrada y registro a lugares cerrados llevada a cabo sin contar la policía con una orden previa ${ }^{37}$.

Pese al cambio de paradigma que propuso el intento de introducir una teoría de prohibiciones probatorias en el sistema procesal chileno de 1906 (o tal vez como consecuencia de lo mismo), en el sentido de reconocer por vez primera la

${ }^{31}$ Por ejemplo, el artículo 323 del CdPP que establece: "Es absolutamente probibido no sólo el empleo de promesas, coacción o amenazas para obtener que el inculpado declare la verdad, sino también toda pregunta capciosa o sugestiva, como sería la que tienda a suponer reconocido un becho que el inculpado no bubiere verdaderamente reconocido [...]".

${ }^{32}$ BofILL, Jorge, Las prohibiciones de prueba en el proceso penal, en RDPUCV., 12 (1988), p. 231.

${ }^{33}$ BofILL, Jorge, Die Beweisverbote im chilenischen Strafprozeß (Erlangen-Nürnberg, 1988).

${ }^{34}$ Bofill, Jorge, Las probibiciones de prueba, cit. (n. 32), pp. 225-243. Ver además: ÉL MisMo, Garantias constitucionales y derecho penal, en GJ., 146 (1992), pp. 7-13; ÉL MISMO, La prueba en el proceso penal, en RDJ., 91 (1994), pp. 17-42.

${ }^{35}$ BofILL, Jorge, Las prohibiciones de prueba, cit. (n. 32), pp. 234 ss.

${ }^{36}$ Ibíd., pp. 236 s.

${ }^{37}$ Ibíd., pp. 237 ss. 
existencia de prueba ilícita, no utilizable, en nuestro ordenamiento, lo cierto es que la tesis de Bofill no encontró acogida en la doctrina ni en la jurisprudencia chilena.

En efecto, la discusión sobre la necesidad de contar con un sistema de ilicitud probatoria en Chile se reactivaría sólo una década más tarde, específicamente con motivo de la discusión y posterior consagración en el nuevo CPP, de una regla de exclusión de prueba por ilicitud, a saber, el conocido artículo 276 inc. $3^{\circ}$ del citado cuerpo legal, disposición que -sabemos-ordena al juez de garantía, en la audiencia de preparación del juicio oral, excluir aquella prueba "que bubiere sido obtenida con inobservancia de garantías fundamentales". Nacía, con dichas palabras, la primera regla de exclusión de prueba por ilicitud consagrada en nuestra legislación positiva ${ }^{38}$.

\section{La recepción de la teoría de las probibiciones probatorias en el sistema consagrado en el} Código Procesal Penal: una propuesta de completitud

La historia legislativa del artículo 276 CPP entrega escasas luces sobre las fuentes o motivaciones tomadas en consideración al momento de consagrarla en el Anteproyecto. La regla actualmente vigente es, en cuanto a su contenido, prácticamente idéntica al artículo 359 del Anteproyecto de CPP, el cual, con una redacción distinta ${ }^{39}$, contenía ya todos los elementos de la regla actual. Esta disposición fue aprobada sin debate alguno en todas las instancias parlamentarias (Camara de Diputados, Senado y Comisión Mixta). La actual redaccion de la regla fue adoptada en el Senado ${ }^{40}$.

\footnotetext{
${ }^{38}$ Posteriormente, las reformas procesales en materia de familia y de justicia laboral incorporaron nuevas hipótesis de exclusión de prueba aplicables a dichos procedimientos. En materia de familia, por ejemplo, el artículo 31 de la ley que establece los tribunales de familia establece: "Exclusión de prueba. El juez de familia, luego de estudiar la admisibilidad de las pruebas ofrecidas, de resolver las convenciones probatorias y de escuchar a las partes que bubieren comparecido a la audiencia preparatoria, ordenará fundadamente que se excluyan de ser rendidas en el juicio aquellas que fueren manifiestamente impertinentes, tuvieren por objeto acreditar hechos públicos y notorios, resulten sobreabundantes o hayan sido obtenidas con infracción de garantias fundamentales. Las demás serán admitidas y se ordenará su rendición en la audiencia de juicio respectiva". En materia de justicia laboral, el artículo 453 del Código del Trabajo establece: "En la audiencia preparatoria se aplicarán las siguientes reglas: [...] 4) El juez resolverá fundadamente en el acto sobre la pertinencia de la prueba ofrecida por las partes, pudiendo valerse de todas aquellas reguladas en la ley. [...] Con todo, carecerán de valor probatorio y, en consecuencia, no podrán ser apreciadas por el tribunal las pruebas que las partes aporten y que se bubieren obtenido directa o indirectamente por medios ilicitos o a través de actos que impliquen violación de derechos fundamentales".

${ }^{39}$ La redacción original de la regla de exclusión contenida en el anteproyecto aludía al problema haciendo referencia al auto de apertura, del siguiente modo: "Artículo 359. Auto de apertura de juicio oral. Al término de la audiencia intermedia el juez de control de la instrucción dictara el auto de apertura del juicio oral. Esta resolución deberá indicar: [...] d) Las pruebas que deberán rendirse en la audiencia oral; $y$, e) La individualización de quienes deban ser citados a la audiencia principal. Para los efectos de lo dispuesto en la letra d), el juez de control de la instrucción admitirá las pruebas ofrecidas por las partes, salvo aquellas que provinieren de actuaciones o diligencias que bubieren sido declaradas nulas, aquellas que bubieren sido obtenidas con inobservancia de garantías fundamentales, las manifiestamente impertinentes, las que tuvieren por objeto acreditar hechos públicos y notorios y todas aquellas que bubieren sido solicitadas con fines puramente dilatorios [...]".

${ }^{40}$ Londoño, Fernando; Martin, Freiwirth; Praetorius, Daniel; Ramírez, José Manuel, Reforma procesal penal: génesis, historia sistematizada y concordancias: Código Procesal Penal (Santiago, 2003), pp. 442 ss.
} 
Tras la entrada en vigencia del CPP, el estudio de la temática conocida entre nosotros como prueba ilícita, cobró una importancia inédita en nuestro país. En el medio chileno, los primeros estudios generados sobre la materia, se centraron fundamentalmente en explicar el contenido y finalidad de la regla de exclusión ${ }^{41}$. A la vez, en la primera década de este siglo, se generaron publicaciones destinadas a exponer el estado de la discusión en los sistemas estadounidense ${ }^{42}$ y alemán ${ }^{43}$, sirviendo ellas de modelo para la recepión (al menos parcial) de dichas posturas por parte de nuestros tribunales. El tiempo develó, sin embargo, que el alcance de la regla de exclusión resulta insuficiente para resolver diversos problemas vinculados a la ilicitud probatoria.

En efecto, como he expuesto en otra oportunidad ${ }^{44}$, la regla de exclusión probatoria contenida en el CPP - con efecto directo en la etapa de preparación del juicio oral- no permite dar solución directa, a lo menos a tres problemas centrales: i) problemas de ilicitud probatoria con incidencia en la etapa de investigación. Éstos se refieren paradigmáticamente a las posibilidades de actuación del juez de garantía al momento de resolver una solicitud formulada en dicha etapa (por ejemplo, una solicitud de ingreso y registro o bien, una solicitud de imposición de medidas cautelares), sustentada en prueba ilícita; ii) problemas de ilicitud probatoria incidentes en el juicio oral. Por regla general, se trata de casos en los cuales se presenta en la audiencia de juicio prueba erróneamente incluida en el auto de apertura, o bien, casos en los cuales la ilicitud de la prueba rendida recién queda de manifiesto en la audiencia de juicio, y por último; iii) problemas asociados al tratamiento de la prueba ilícita en aquellos procedimientos especiales regulados en el CPP, y que no contemplan una instancia formal de discusión de ilicitud probatoria ( $v . g r$. procedimiento abreviado o procedimiento por crimen o simple delito de acción penal privada).

Precisamente, como mecanismo de solución a los problemas antes mencionados es que parte de la doctrina chilena ${ }^{45}$ ha buscado dar aplicación a la teoría de las prohibiciones probatorias, impidiendo -por medio de su reconocimiento- al tribunal fundamentar una resolución judicial en cualquier estado del procedimiento, en base a prueba ilícitamente obtenida. En efecto, el respeto a las garantías fundamentales reconocidas por nuestro ordenamiento jurídico impone un deber a todo órgano que ejerce jurisdicción en lo penal, de no valerse de prueba en cuya obtención dichas garantías fueron infringidas. Lo anterior debiera regir incluso fuera del alcance directo de la regla de exclusión de prueba.

Dichos lineamientos han sido recogidos por nuestros tribunales superiores de

\footnotetext{
${ }^{41}$ En este sentido, paradigmáticamente: HeRnández, Héctor, Exclusión de la prueba ilícita en el nuevo proceso penal chileno (Santiago, 2005); Zapata, Francisca, La prueba ilícita (Santiago, 2004).

${ }^{42}$ Zapata, Francisca, La prueba ilicita, cit. (n. 41), pp. 27 ss.

${ }^{43} \mathrm{El}$ artículo de Ambos, Kai, Las prohibiciones de utilización de pruebas en el proceso penal alemánfundamentación teórica y sistematización, cit. (n. 9), passim, presenta la que hasta la fecha constituye la mejor exposición pormenorizada de la teoría de las prohibiciones probatorias publicada en Chile.

${ }^{44}$ Correa, Carlos, Más allá de la regla de exclusión: probibiciones probatorias, cit. (n. 30), pp. $155 \mathrm{ss.}$

${ }^{45}$ Ibíd., pp. 164 ss.; Hernández, Héctor, Prueba ilícita y recurso de nulidad: (o ¿Para qué está la Corte Suprema), en GJ., 332 (2008), p. 60; HernÁndez, Héctor, Exclusión de la prueba ilícita, cit. (n. 41), pp. 89 ss.
} 
justicia, los cuales, valiéndose de la (cuestionable) expresión "valoración negativa de la prueba", han reconocido la existencia residual de prohibiciones de valoración de prueba, impidiendo que prueba ilícitamente obtenida sirva de fundamento a una resolución pronunciada por un tribunal penal. Paradigmáticamente, en una sentencia recientemente dictada en causa $\mathrm{Rol} \mathrm{N}^{\circ} 375-2019$, sostuvo la Corte de Apelaciones de Valparaíso (considerando $7^{\circ}$ ) que: “[...] ante la constatación de que en el juicio se aportó una prueba ilícita, el Tribunal de Oral en lo Penal debe valorarla negativamente, pudiendo examinarse los medios probatorios existentes, en virtud del principio de inmediación y de contradictoriedad; no siendo posible que los sentenciadores formen su convicción de condena sobre la base de una prueba que consideran obtenida ilegalmente".

El reconocimiento de dichas prohibiciones probatorias residuales en el sistema chileno, se ha sostenido, rige con independencia de lo resuelto en la audiencia de preparación del juicio oral en relación a una exclusión de prueba. Así, en un fallo de la Corte Suprema (Rol 6783-2017) se decantó el máximo tribunal a favor de la procedencia de la valoración negativa de la prueba, señalando de manera categórica (considerando $5^{\circ}$ ) que dicha: "teoría constituye una instancia más -adicional al control de detención y la audiencia de preparación de juicio oral- para discutir y probar la ilicitud de la prueba de cargo".

Concordante con dicha postura, sostuvo la Corte de Apelaciones de Valparaíso en el ya citado fallo Rol N 375-2019 (considerando $7^{\circ}$ ) que: "El artículo 276 del Código Procesal Penal impide que los jueces puedan valorar positivamente una prueba lograda con vulneración de las garantías constitucionales de los imputados. La circunstancia que ya haya existido previamente un pronunciamiento sobre el particular por parte del juez de garantía, no es óbice para decidir la valoración negativa de la prueba ilícita. Más aún, el Tribunal Oral en lo Penal debe prescindir de esta prueba, pues lo contrario llevaría a concluir que dicho tribunal debe fallar en la conciencia y conocimiento de la vulneración de garantías constitucionales y procesales de los imputados".

\section{CONCLUSIONES}

A partir de lo expresado, resulta impropio e injusto analizar la obra de Beling a partir de la concepción actual del proceso penal. Dicho autor jamás entendió las prohibiciones de prueba como una consecuencia directa e inevitable de toda infracción a una regla de producción de prueba, sino como una respuesta frente a infracciones a reglas de producción de prueba expresamente tipificadas por el legislador.

En este sentido, no resulta correcto imputarle a dicho autor la defensa de una absurda concepción ilimitada de las prohibiciones probatorias, al acercarse su postura justamente a lo contrario. Sus hipótesis de prohibición probatoria mencionadas, correspondían a unos pocos casos legalmente reconocidos, en los cuales el legislador expresamente decidió restringir la averiguación de la verdad, proscribiendo la obtención de ciertos resultados o métodos probatorios.

Tras el cambio de paradigma introducido al proceso penal en las últimas décadas, en orden a entender como únicas vías lícitas para la averiguación de la 
verdad la utilización de información obtenida mediante diligencias de investigación expresamente reguladas por el legislador y dando estricto cumplimiento a los requisitos exigidos para su realización, el campo de aplicación de la teoría modelada inicialmente por Beling se ha expandido notablemente. Actualmente, la teoría de las prohibiciones probatorias permite sancionar por esta vía prácticamente cualquier infracción cometida por órganos de persecución penal a reglas sobre obtención de material probatorio, impidiendo a un tribunal penal formar su convicción en base a éstas.

Como consecuencia del amplio reconocimiento y alcance del que actualmente goza dicha teoría en el derecho procesal penal, su rendimiento práctico le permite brindar respuesta a diversos problemas de ilicitud probatoria cuya solución no ha venido de la mano del legislador, sobrepasando de este modo las fronteras en las cuales dicha teoría fue inicialmente concebida. Así, la teoría originalmente propuesta por Beling como el reconocimiento de un límite a la averiguación de la verdad, resulta susceptible de ser aplicada en aquellos sistemas de raigambre jurídica continental, y que no regulan, o a lo menos no lo hacen de manera íntegra, problemas de ilicitud probatoria en virtud de la obtención de un medio de prueba cuestionado. Chile es un claro ejemplo de ello.

La concepción actualmente vigente de la teoría de las prohibiciones de valoración de prueba, que supedita el reconocimiento de éstas a la constatación de una infracción a una regla de obtención probatoria, permite dar tratamiento a diversos problemas no contemplados dentro del alcance directo de la regla de exclusión probatoria del artículo 276 inc. $3^{\circ} \mathrm{CPP}$. Su tratamiento por parte de la jurisprudencia chilena es, en este sentido, un caso de recepción jurídica digno de mención.

En efecto, el principal rendimiento atribuible hoy en día a la teoría de las prohibiciones probatorias es que permite a cualquier tribunal con competencia en lo penal, sin necesidad de contar con una regla expresa, descartar la valoración de determinados medios de prueba ilícitamente obtenidos. Igualmente, como ha recalcado el máximo tribunal chileno, dicha solución no presenta contradicción alguna con el reconocimiento expreso de una regla de exclusión de prueba sino que por el contrario, se entiende como una complementación de la misma, actuando ya sea en situaciones en las que dicha regla no brinda solución alguna o bien, donde erróneamente no ha sido aplicada.

\section{BiBLIOGRAFÍA}

Alsberg, Max; Nüse, Karl-Heinz; DallmeYer, Jens, Der Beweisantrag im Strafprozess (6 ed., Köln y otros, 2013).

Aмвos, Kai, Las probibiciones de utilización de pruebas en el proceso penal alemán-fundamentación teórica y sistematización, en Polít. Crim., 7 (2009), pp. 1-56.

BELING, Ernst. Die Beweisverbote als Grenzen der Wabrheitserforschung im Strafprozess: Sonderausgabe, (Breslau, 1903, Reimp. Darmstadt, 1968).

-Grenzlinien zwischen Recht und Unrecht in der Ausübung der Strafrechtspflege (Tübingen, 1913). 
—Deutsches Reichsstrafprozeßrecht: mit Einschluß des Strafgerichtsverfassungsrechts (Berlin y otros, 1928).

BeulKe, Werner, Hypothetische Kausalverläufe im Strafverfahren bei rechtswidrigem Vorgehen von Ermittlungsorganen, en ZStW., 103 (1991), pp. 657-680.

Bofill, Jorge, Die Beweisverbote im chilenischen Strafprozeß, Diss. (Erlangen-Nürnberg, 1988).

—Garantías constitucionales y derecho penal, en GJ., 146 (1992), pp. 7-13.

-La prueba en el proceso penal, en RDJ., 91 (1994), pp. 17-42.

—Las probibiciones de prueba en el proceso penal, en RDPUCV., 12 (1988), pp. 225-243.

Correa, Carlos, La buena fe del agente como excepción a la aplicación de la regla de exclusión - derecho estadounidense y derecho chileno-, en LALS., 2 (2018), pp. 25-50.

-Más allá de la regla de exclusión: probibiciones probatorias en el Derecho chileno - con especial referencia al derecho alemán-, en Polit. crim., 25 (2018), pp. 144-174.

Dallmeyer, Jens, Beweisfübrung im Strengbeweisverfahren (2 ed., Norderstedt, 2008).

Dencker, Friedrich, Über Heimlichkeit, Offenheit und Täuschung bei der Beweisgewinnung im Strafverfabren - Anmerkungen aus Anlaß zweier Entscheidungen des BGH - en $S t V$., 5 (1994), pp. 667-683.

-Verwertungsverbote im Strafprozeß: ein Beitrag zur Lehre von den Beweisverboten (Köln y otros, 1977).

EISEnBERG, Ulrich, Beweisrecht der StPO: Spezialkommentar (9 ed., München, 2015).

Gössel, Karl Heinz, Kritische Bemerkungen zum gegenwärtigen Stand der Lehre von den Beweisverboten im Strafverfahren, en NJW., (1981), pp. 649-657.

—Einleitung L, en Becker, Jörg-Peter; Erb, Volker; Esser, Robert; GraAlmannScheerer, Kirsten; Hilger, Hans; Ignor, Alexander (eds.), Löwe-Rosenberg: Die Strafprozeßordnung und das Gerichtsverfassungsgesetz. Großkommentar, 27. Ed. Primer Tomo: Introducción, $\iint 1$ 1-47, (Berlin y otros, 2016).

Grünwald, Gerald, Das Beweisrecht der Strafprozeßordnung (Baden-Baden, 1993).

Hengstenberg, Achim, Die Frühwirkung der Verwertungsverbote: eine Untersuchung der Bedeutung der Beweisverwertungsverbote für die strafprozessualen Verdachtsbeurteilungen (Hamburg, 2007).

Herdegen, Gerhard, Bemerkungen zur Lehre von den Beweisverboten, en: II. StrafverteidigerFrübjahrssymposium 1988 der Arbeitsgemeinschaft Strafrecht des Deutsches Anwaltverein. Wabrbeitsfindung und ibre Schranken (Bergisch Gladbach, 1989), pp. 103-121.

HeRNÁNDEZ, Héctor, Exclusión de la prueba ilícita en el nuevo proceso penal chileno (Santiago, 2005).

—Prueba ilícita y recurso de nulidad: (o ¿Para qué está la Corte Suprema), en GJ., 332 (2008), pp. 60-68.

KelnHofer, Evelyn, Hypothetische Ermittlungsverläufe im System der Beweisverbote (Berlin, 1994).

Knauth, Alfons, Beweisrechtliche Probleme bei der Verwertung von Abhörmaterial im Strafverfahren, en $N J W$.,

(1978), pp. 741-745.

KohlhaAs, Max, Beweisverbote im Strafprozeß, en DRiZ., 44 (1966), pp. 286-291.

Koriath, Heinz, Über Beweisverbote im Strafproze $\beta$ (Frankfurt am Main y otros, 1994).

KüHNE, Hans-Heiner, Strafprozessrecht: eine systematische Darstellung des deutschen und europä̈schen Strafverfahrensrechts (9 ed., Heidelberg y otros, 2015).

Londoño, Fernando; Martin, Freiwirth; Praetorius, Daniel; Ramírez, José Manuel, 
Reforma procesal penal: génesis, historia sistematizada y concordancias: Código Procesal Penal (Santiago, 2003).

Maul, Heinrich; EschelbaCH, Ralf, Zur “Widerspruchslösung” von Beweisverbotsproblemen in der Rechtsprechung, en StraFo., (Mayo/Junio 1996), pp. 66-70.

Meyer-Gossner, Lutz; Schmitt, Bertram, Strafprozessordnung. Gerichtsverfassungsgesetz, Nebengesetze und ergänzende Bestimmungen (59 ed., München, 2016).

Peters, Karl, Strafprozeß: ein Lebrbuch (4 ed., Heidelberg, 1985).

PIтSCH, Christoph, Strafprozessuale Beweisverbote: eine systematische, praxisnabe und rechtsvergleichende Untersuchung unter besonderer Berücksichtigung des Steuerstrafverfahrens, der Zufallsfunde und der Fernwirkungsproblematik. (Hamburg, 2009).

RogaLL, Klaus, Gegenwärtiger Stand und Entwicklungstendenzen der Lehre von den strafprozessualen Beweisverboten, en ZStW., 91 (1979), pp. 1-44.

-Grundsatzfragen der Beweisverbote, en HÖPFL, Frank y HüBER, Barbara (ed.), Beweisverbote in Ländern der EU und vergleichbaren Rechtsordnungen, Exclusion of Evidence Within the EU and Beyond, Europäisches Kolloquium Wien, 18. - 20. September 1997 (Freiburg i. Br., 1999), pp. 119-148.

—Beweiserhebungs- und Beweisverwertungsverbote im Spannungsfeld zwischen den Garantien des Rechtsstaates und der effektiven Bekämpfung von Kriminalität und Terrorismus, en JZ., 17 (2008), pp. 818-830.

—Grund und Grenzen der "qualifizierten” Belehrung im Strafprozess, en: GeIsLER, Claudius; Kraatz, Erik; Kretschmer, Joachim; Schneider, Hartmut; Sowada, Christoph (eds.), Festschrift für Klaus Geppert zum 70. Geburtstag am 10. März 2011 (Berlin y otros, 2011), pp. 519-547.

Schellhammer, Kurt, Blutentnahme durch Medizinalassistenten, en NJW., 7 (1972), pp. 319-320.

Schlothauer, Reinhold, Zur Bedeutung der Beweisverwertungsverbote im Ermittlungs- und Zwischenverfahren, en PritTwitz, Cornelius; Baurmann, Michael; Günther, Klaus; Kuhlen, Lothar; Merkel, Reinhard; Nestler, Cornelius; Schulz, Lorenz (eds.), Festscbrift für Klaus Lüderssen zum 70. Geburtstag am 2. Mai 2002 (Baden-Baden, 2002), pp. 761-772.

STÖRMER, Rainer, Dogmatische Grundlagen der Verwertungsverbote: eine Untersuchung über die Strukturen strafprozessualer Verwertungsverbote unter dem Einfluss der Verfassung und der Grundsätz̨e des öffentlichen Recbts (Marburg, 1992).

— Strafprozessuale Verwertungsverbote in verschiedenen Konstellationen, en JURA., 8 (1994), pp. 621-628.

STRATE, Gerhard, Rechtshistorische Fragen der Beweisverbote, en II. Strafverteidiger-Frübjabrssymposium 1988 der Arbeitsgemeinschaft Strafrecht des Deutsches Anwaltverein. Wabrheitsfindung und ibre Schranken (Bergisch Gladbach, 1989), pp. 13-20.

Zapata, Francisca, La prueba ilícita (Santiago, 2004). 